\title{
Diagnosing Diffusion Practices Within a Software Organization
}

\author{
Ingegerd Andersson ${ }^{1}$ and Kerstin Nilsson ${ }^{2}$ \\ ${ }^{\prime}$ Volvo Information Technology, Dept. 9714, HCIS, S-40508 Göteborg, SWEDEN \\ ${ }^{2}$ The Viktoria Institute, Göteborg University, P.O. Box 620, S-40530 Göteborg, SWEDEN
}

Key words: Diffusion and adoption, software technology, diagnostic approach.

\begin{abstract}
New software development methods, tools, and techniques are being developed at an increasing pace. To take advantage of this new technology, organizations struggle to implement at a similar pace. There is an increasing awareness that the expected benefits are not being achieved. To remedy this situation, software organizations need to better understand the weaknesses of current diffusion practices.

This paper presents lessons from a large software organization in which the diffusion practices were diagnosed. The diagnosis relied on state-of-the-art theories and combined mapping techniques, workshops, and in-depth interviews to gain insights into current practices. The paper offers practical advice on how to diagnose diffusion practices within software organizations and contributes to the understanding of key issues in these practices.
\end{abstract}

\section{INTRODUCTION}

Software organizations spend a lot of effort on developing and introducing new software technologies. however, the expected results-in terms of improved software quality or increased productivity-are often not achieved (Huff 1992; Lyytinen and Hirschheim 1987; Pressman 1997; Weinberg 1997). On a more general level, numerous research efforts have explored issues related to diffusion and adoption of information technology (Cooper and Zmud 1990; Eason 1988; Kautz 1995; León 1995; Markus

The original version of this chapter was revised: The copyright line was incorrect. This has been corrected. The Erratum to this chapter is available at DOI: 10.1007/978-0-387-35404-0_19 
1983; Mathiassen and Sørensen 1997; Mitroff and Linstone 1993; The Standish Group 1995). Thus, it is by now well-known in the research community that diffusion and adoption of IT is a complex task that requires attention and planning. However, this knowledge does not seem to reach practitioners within software organizations.

In order to improve any activity, one must establish knowledge about current practices. This knowledge is needed for developing useful improvement strategies that tackle existing problems and barriers and thereby lead to improved practices (Checkland and Scholes 1990; Humphrey 1990; Lanzara and Mathiassen 1985; Pressman 1997). In this paper, we offer practical advice on how to diagnose diffusion practices within software organizations and contribute to the understanding of the key issues in diffusion efforts.

Our findings are based on a diagnostic project conducted at Volvo IT $\mathrm{AB}$, a large Swedish software organization with approximately 2,500 employees worldwide. One thousand of these employees are involved in systems development and maintenance. A department called "Common Skills and Methods" (CSM) has the responsibility to "direct, develop and maintain methodologies and tools used in the systems development process." Each year a number of implementation projects are conducted within this department. The purposes of these projects, ranging from one man-month to six man-years, are to implement new methods, tools, and techniques. The diffusion practices applied in this department were the targets for the diagnosis performed.

We chose to use a case study approach for our research. This approach provided us with a means to gain a rich insight into the organizational phenomenon of diffusion practices (Yin 1994). Our case, the diagnostic project at Volvo IT AB, relied on state-of-the-art theories (Checkland and Scholes 1990; Cooper and Zmud 1990; Eason 1988; Huff 1992; Kautz 1995; León 1995; Markus 1983; Mathiassen and Sørensen 1997; The Standish Group 1995; Weinberg 1997) and combined mapping techniques (Checkland and Scholes 1990; Lanzara and Mathiassen 1985), workshops (Fredriksen et al. 1998), and in-depth interviews (Patton 1990) to gain insights into current practices. In order to categorize data and find essential relationships, a grounded theory approach was used in the workshop setting(Strauss and Corbin 1990). In conducting the project we drew on experiences from similar attempts in a Danish software organization (Fredriksen et al. 1998).

Our argument is structured as follows: Section 2 presents insights from the IT diffusion literature together with the diagnostic approaches that we applied in the software organization. We present the diagnostic process and

${ }^{6}$ Official presentation is on the corporate intranet (http://violin.it.volvo.se/dept/it9710). 
results in section 3 . The findings regarding both diffusion issues and the diagnostic process are discussed in section 4 . The paper ends with a conclusion in section 5 .

\section{DIAGNOSTIC FOUNDATION}

Diagnosing a diffusion practice has two sides to it: the diagnostic result, which is a measure of some important characteristics of a diffusion effort, and the diagnostic techniques applied to unveil these characteristics. We consider each of these in turn.

\subsection{Diagnostic result}

In choosing diffusion characteristics to diagnose, we have utilized knowledge from research related to problems with diffusion and adoption of IT in general. A survey of this research shows that there are three major directions that can be identified: factor research, process research, and political research (Cooper and Zmud 1990). These three research areas have helped us identify key characteristics of the diffusion practices at Volvo IT. We will describe the diffusion characteristics of each research area and the measures we have used to diagnose these characteristics.

Factor research focuses on individual, organizational, and technological forces that enable diffusion effectiveness. These enablers are discussed in a number of papers (Cooper and Zmud 1990; Huff 1992; Kautz 1995; León 1995; Mathiassen and Sørensen 1997; McMaster and Vidgen 1995; The Standish Group 1995). As a means for diagnosing enablers we have chosen to evaluate six of the most frequently mentioned enablers from the papers above:

- Top management support for the diffusion effort ensures credibility and attention in the organization.

- A clear statement of underlying reasons and the intended goals sets the scope and focus for the diffusion effort and prevents inadequate expectations.

- Goals and implementation rationale must be communicated throughout the organization, and appropriate communication with stakeholders must be initiated and maintained.

- Skills development is a very important part of a diffusion effort.

- Monitoring and evaluation of goals makes it possible to control and direct the diffusion effort.

- Good IT design that fits organization structure and work patterns ensures a smooth diffusion and adoption process. 
Process research focuses on social change activities and management of the diffusion process (Cooper and Zmud 1990; Eason 1988; Huff 1992; Weinberg 1997). The diagnosis of the diffusion process is based on classifications of the change model and the implementation strategy involved. To diagnose the change activities, we used Weinberg's classification of change models (Weinberg 1997). His four models provide a means to measure the ability to control and direct the change process:

- The diffusion model is based on the theory that change more or less happens without interference. Change is unpredictable, both in time and space, and can degenerate on the way.

- The hole-in-the-floor model is based on the diffusion model but adds control. The idea is that if change is planned correctly, it will diffuse in a controlled manner. However, this model leaves out the human factor. It assumes that the receiver should understand why and how to use what is being diffused.

- The Newtonian model is based on Newton laws: To change in a certain direction, you must push in that direction, and the bigger the system and the faster you want the change, the harder you must push. This strategy works for a period of time, but then people probably get tired and less productive and make more mistakes. Thus, one problem is that the force can come back as a boomerang or it can go in another direction.

- The learning curve model is based on the assumption that people cannot respond instantly to change but need a certain time to learn and respond. The curve is affected by a number of psychological factors, such as relevant skill, motivation, and attitude. It suggests that projects manage the change with personal selection and training.

Management of the diffusion process is diagnosed using Eason's classification of implementation strategies (Eason 1988). These strategies provide a means to measure the level of planning applied as well as the management of the actual implementation process.

- The Big Bang strategy means instant changeover. This is necessary sometimes, but it requires careful planning because everything from technology to organization has to work simultaneously. After the change, extra resources are needed, and organizational performance usually declines initially.

- The parallel running strategy means running the old system in parallel with the new. This strategy provides an insurance policy against failure, but there is inevitably a cost involved in handling two types of work simultaneously. A problem with this strategy is how and when to make 
organizational changes, because it is impossible to maintain two parallel organizations at the same time.

- The phase introduction strategy means introducing the change slowly over a period of time. This can be achieved by introducing the change in phases or by addressing the organization one part at a time. The phase introduction strategy lets users get used to the change at a suitable pace. However, each group has the same capability to learn; thus, the last group requires the same attention as the first.

- The trials and dissemination strategy means that a small-scale implementation with one group is used to test the change before it is introduced on a wider basis. This strategy is based on the assumption that most problems will be solved after the trial period, and therefore, the implementation in the rest of the organization will go smoothly. Careful planning and participation of each new group in the implementation process is important, because lessons from the implementation in one group may not apply to the rest of the organization.

- The infrastructure and incremental application strategy is a mixture of strategies whose common themes are evolution and local, user-led design. Three infrastructure elements are necessary: technical support, implementation support, and organizational policies. The key is to balance between user freedom and organizational control.

Political research, finally, acknowledges the need to manage the different interests of diffusion stakeholders (Checkland and Scholes 1990; León 1995); (Markus 1983; Mitroff and Linstone 1993). Political interaction theory suggests that implementing new information systems often changes power positions in an organization. The ones who lose power are likely to resist the change. Identifying and predicting resistance will help prevent it or deal with it if it arises (Markus 1983). As a means of identifying diffusion stakeholders, their interests, and relations, we have used rich pictures, described in (Checkland and Scholes 1990).

\subsection{Diagnostic techniques}

The diagnosis was performed both at a general and a project level. The reason for this was to complement findings regarding common problems and patterns with findings from specific projects.

We used a workshop setting to diagnose at the general level. This is the same approach as was used in the Danish project (Fredriksen et al. 1998). The workshop was conducted as a structured brainstorm with a number of activities. First the participants were asked to identify problems related to diffusion and adoption. The problems were then categorized and condensed 
to a manageable number. Finally, the identified problems were related to each other using a relation diagram (Fredriksen et al. 1998). A relation diagram shows how actions-or, as in our case, diffusion and adoption problems-relate to each other and which problems are the major cause of others.

At the project level, we used a combination of diagnostic techniques, including in-depth interviews (Patton 1990; Yin 1994), diagnostic maps, ecological maps (Lanzara and Mathiassen 1985), and rich pictures (Checkland and Scholes 1990).

Interviews provide a means to gain important insights into specific situations. In our case, we needed in-depth understanding about the whole process of specific projects, as perceived by the involved actors. The interview technique used was standardized open-ended. We chose this technique because the practitioners that we interviewed were very busy, and the open-ended interview technique is considered suitable when there is limited time available for interviews (Patton 1990).

Diagnostic maps were used to focus the interviews. These maps are a useful tool for locating and describing existing problems and dysfunctions in projects, as perceived by the involved actors (Lanzara and Mathiassen 1985). For each problem discovered, the following questions were asked: What happened? Why is it a problem? What are the consequences? What can be done? During the questioning, new problems can be discovered and broken down.

Ecological maps (Lanzara and Mathiassen 1985) describe how problems in a situation can be related to the surrounding environment. These maps summarize problems identified by diagnostic maps and relate them to either internal or external conditions .

Rich pictures, from Soft Systems Methodology, describe actors, relations, and conflicts, as perceived by the involved actors (Checkland and Scholes 1990).

\section{DIAGNOSTIC PRACTICE}

In this section we will describe the diagnosis performed. First the diagnostic process and its context are described and then the diagnostic result is presented. 


\subsection{Diagnostic process}

Volvo IT implements and maintains all IT solutions at Volvo. Volvo IT's objectives are to create results for the business, with emphasis on speed of delivery, flexibility, responsiveness and accountability for results.

Department Common Skills and Methods (CSM) is a knowledge center within Volvo IT; there are approximately 120 employees in the department. CSM has the responsibility to support system development at Volvo IT with tools and knowledge. A Strategy and Coordination group within CSM directs several projects (15 man-years in total) with the main focus on diffusion and adoption of new methodologies and tools.

Preceding this study there was no documented knowledge of CSM's ability to diffuse and implement new technologies. To find out how CSM managed diffusion and adoption, we arranged a workshop and conducted indepth interviews with actors in specific diffusion projects.

The intention of the workshop was to get a general view of common problems in relation to diffusion and adoption of new technologies. Participants chosen had at least 2 years (some more than 20 years) of experience with diffusion and adoption projects in the organization. They represented parts of the organization involved in diffusion efforts conducted by CSM. Participants were chosen with the intention of getting views on current diffusion and adoption practices from different perspectives. Their occupations were: a SDSM manager, a SDSM strategist, two project leaders, a methodologist, a manager for a department introducing new techniques in the Web area, and a manager for a group which handles CSM's R\&D resources. 


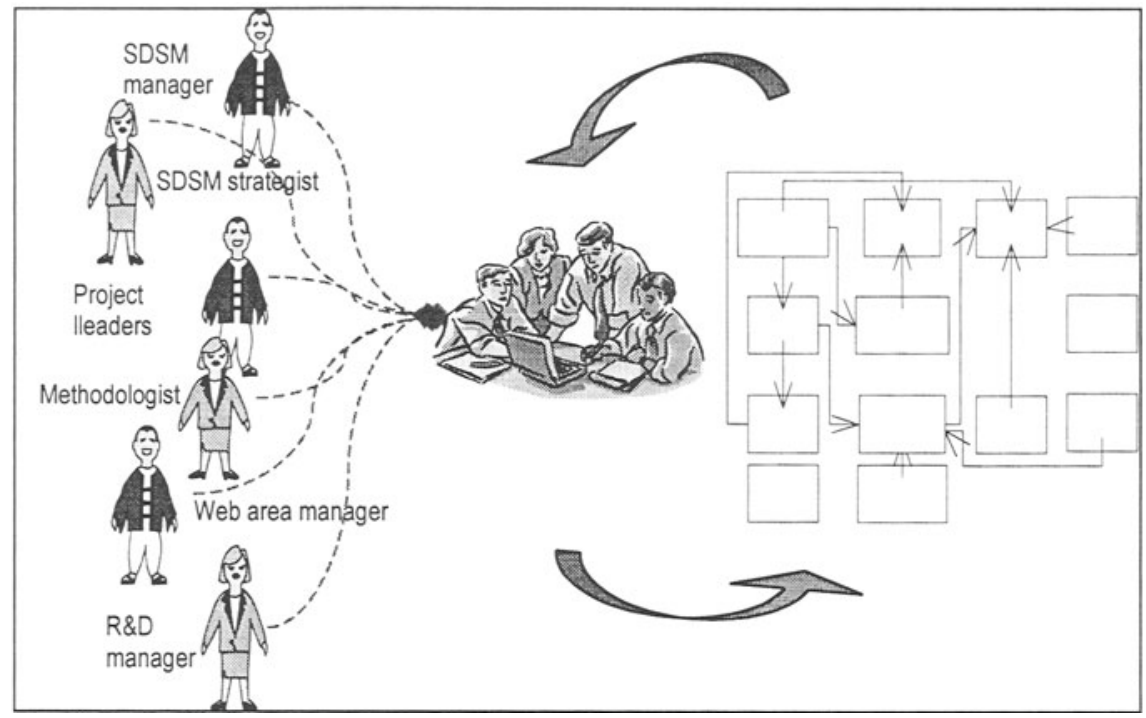

Figure 1. Diagnostic process, general level

The workshop was organized as a discussion, where the participants were asked to consider the following scenario: "You are asked to diffuse and adopt a new technology or method from CSM into your organization. What are your concerns and objections?" Figure 1 describes the process where the open workshop resulted in a relation diagram. The problems identified during the discussion were categorized, condensed, and used as a basis for the relation diagram presented in figure 2. Each workshop participant then verified the relation diagram. 


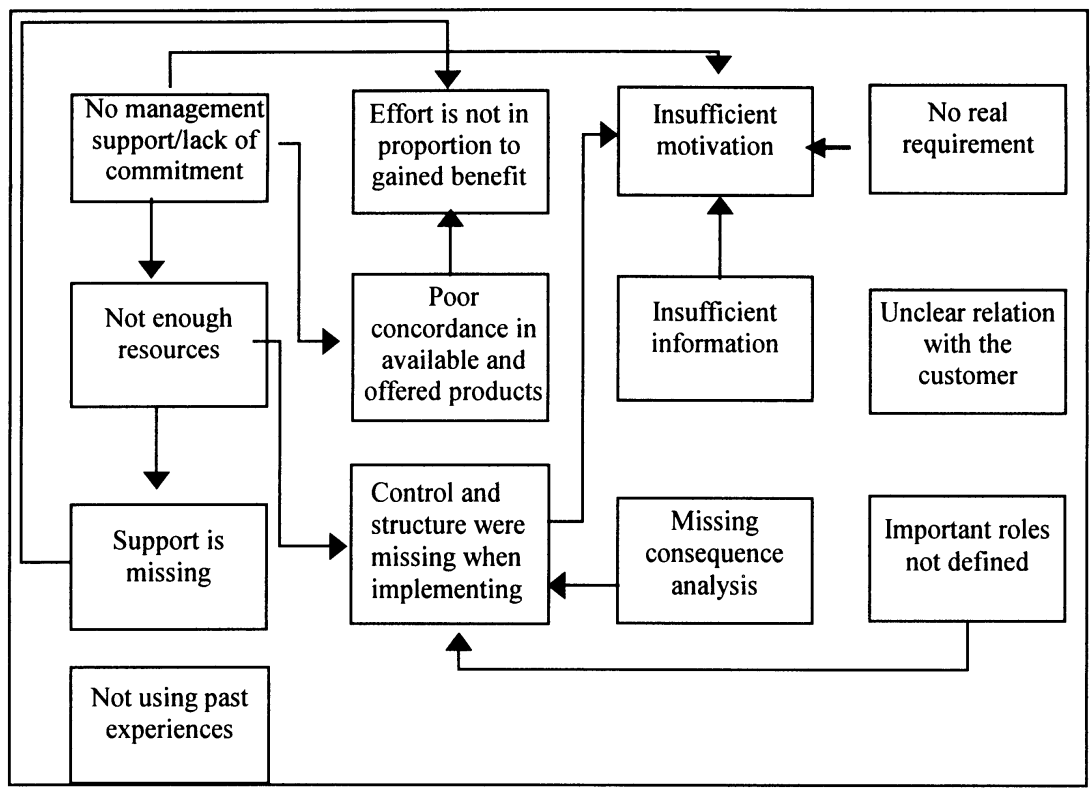

Figure 2. Relation diagram, showing common diffusion issues

Additionally, we interviewed four implementation projects, where two were deployed in the organization and two were on their way to being deployed. When choosing the projects, we considered: how big they were, whether their product was implemented, and if their target group was Volvo IT globally or only sub-units of Volvo IT. We wanted the projects to be different in these aspects. All of the projects had project leaders from CSM. The selected projects were:

- Project 1: 65 person-months, delivered a model to Volvo IT Sweden.

- Project 2: 50 person-months, delivered a method to Volvo IT globally.

- Project 3: 15 person-months, delivered a method to Volvo IT Sweden.

- Project 4: 0.5 person-months, delivered a tool to Volvo IT globally.

For each project, we interviewed two persons: one provider and one receiver of the product. They were interviewed separately, and each interview lasted approximately one hour. Because of the limited time and budget available, all persons interviewed were from Sweden. One person conducted the interview and the other documented it. The interviews started with general questions in which the interviewee was asked to describe the product: it's target group, when it was implemented, and how it was implemented. Then, the diagnostic mapping technique was used to identify five of the biggest problems experienced by the interviewee during the implementation phase (see appendix for an example). 


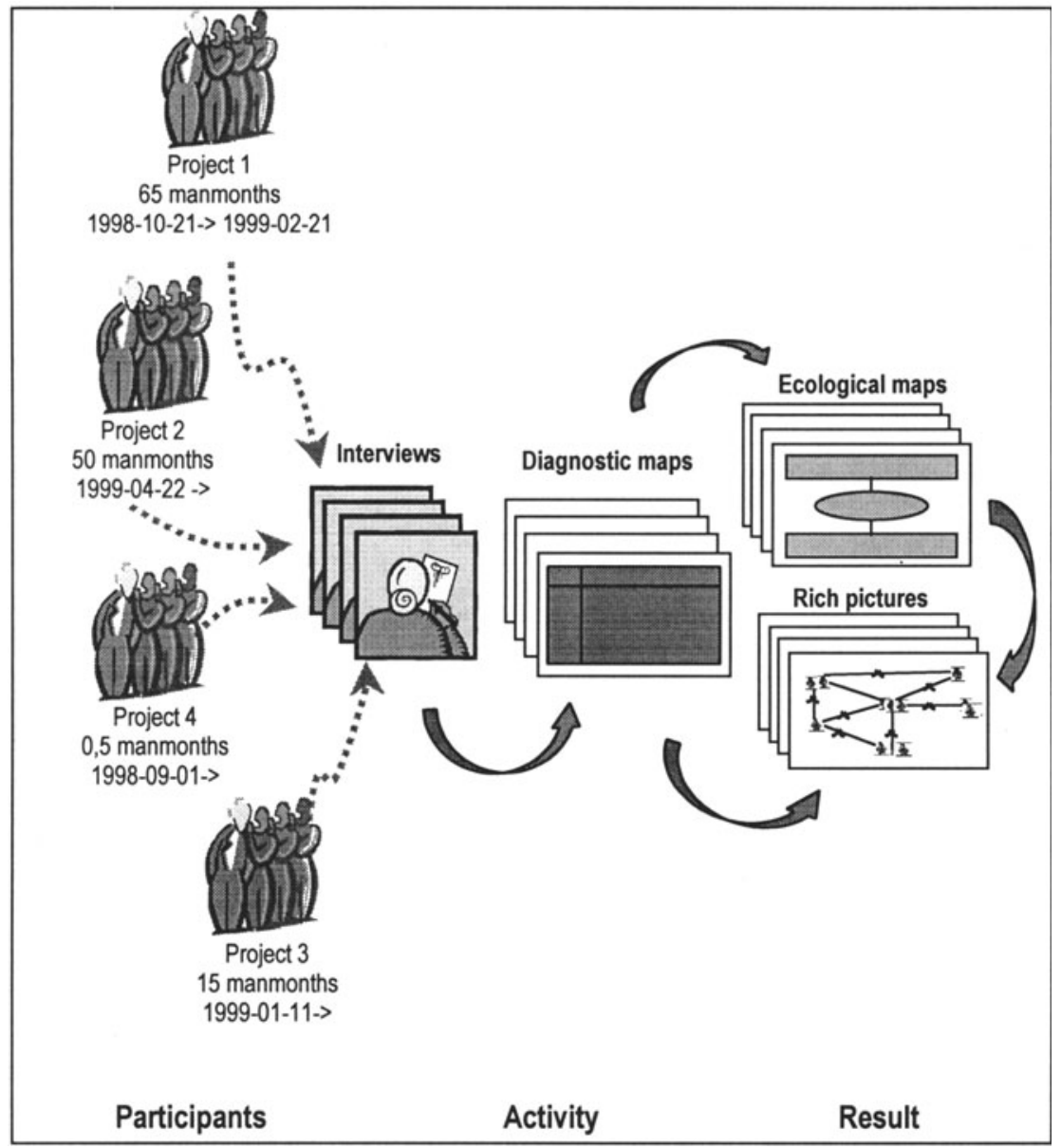

Figure 3. Diagnostic process, project level

After the interviews the diagnostic maps were synthesized in an ecological map. The problem causes identified in these ecological maps were later categorized into general types of conditions to easier identify patterns (see appendix for an example). We also checked against the available project documentation to see if the causes and consequences were mentioned there.

To identify stakeholders and their conflicting interests, we used rich pictures. Both the diagnostic maps and the ecological map were used as inputs to the rich pictures. The diagnostic process is illustrated in figure 3. 


\subsection{Diagnostic result}

The documentation from the diagnosis at the project level (diagnostic maps, ecological maps, and rich pictures) was structured using the three directions of diffusion and adoption research: factor, process, and political. Table 1 summarizes the results found for each area.

Table 1. Factors and diffusion processes identified in the four projects

\begin{tabular}{|c|c|c|c|c|c|}
\hline \multicolumn{2}{|c|}{ the } & Project 1 & Project 2 & Project 3 & Project 4 \\
\hline \multirow{6}{*}{ 递 } & $\begin{array}{l}\text { Top management } \\
\text { support }\end{array}$ & + & + & - & - \\
\hline & $\begin{array}{l}\text { A clear statement } \\
\text { of underlying } \\
\text { reasons and } \\
\text { intended goals }\end{array}$ & + & + & - & - \\
\hline & $\begin{array}{l}\text { Goals and } \\
\text { implementation } \\
\text { rationale } \\
\text { communicated }\end{array}$ & - & + & + & - \\
\hline & Skills development & - & + & - & - \\
\hline & $\begin{array}{l}\text { Monitoring and } \\
\text { evaluation of goals }\end{array}$ & - & - & + & - \\
\hline & Good IT design & - & + & + & - \\
\hline \multirow{4}{*}{ 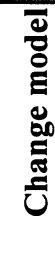 } & Diffusion model & & & & $\bar{X}$ \\
\hline & $\begin{array}{l}\text { Hole-in-the-floor } \\
\text { model }\end{array}$ & $\mathrm{X}$ & & & \\
\hline & Newtonian model & & & & \\
\hline & $\begin{array}{l}\text { Learning curve } \\
\text { model }\end{array}$ & & $\mathrm{X}$ & $\mathrm{X}$ & \\
\hline \multirow{5}{*}{ 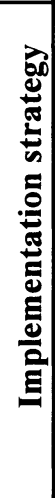 } & Big bang strategy & $\bar{X}$ & & & \\
\hline & $\begin{array}{l}\text { Parallel running } \\
\text { strategy }\end{array}$ & & & & \\
\hline & $\begin{array}{l}\text { Phase introduction } \\
\text { strategy }\end{array}$ & & $\mathrm{X}$ & $\mathrm{X}$ & \\
\hline & $\begin{array}{l}\text { Trials and } \\
\text { dissemination } \\
\text { strategy }\end{array}$ & & $\mathrm{X}$ & & \\
\hline & $\begin{array}{l}\text { Infrastructure and } \\
\text { incremental } \\
\text { strategy }\end{array}$ & & & & \\
\hline
\end{tabular}

+/- Denotes whether the factor was present/planned at the time we diagnosed. 


\subsubsection{Project 1}

Project 1 had top management support. The project's goals were clearly defined, but there was no direct communication with stakeholders. Monitoring and evaluation of the project's goals was not done. Skill development was not taken care of in the project; it was considered a postdiffusion issue. A two-day course was offered after the release, but it was not required and not many attended it. The implementation strategy for Project 1 was clearly a Big Bang with instant changeover, as the product was introduced everywhere in the organization on the same day. Unfortunately the product (a model) was not ready and the planned support organization was not fully established at the release date, causing a negative attitude in the organization. The change model was hole-in-the-floor; the project had no intention of controlling the diffusion after the release date; instead, that responsibility was placed on middle management. Conflicting interests and ambitions between top and middle management were found. Middle management did not see the benefits of the model, which was just considered as extra work for their employees, to whom they filtered the information. Usage of the model was mandatory, but as middle management did not prioritize the implementation, it was difficult to motivate any education.

\subsubsection{Project 2}

Top management support was present. The project's goals and rationale were clear and communicated throughout the organization. Skills development was addressed, but there was a shortage of educated mentors in the beginning. Even so, the project received a lot of goodwill and positive feedback through its education program. Project 2 used both trial and dissemination strategy and phase introduction strategy, as they started with a few pilots and then chose to implement one project at a time in a controlled way. Each pilot had planned extra time for participants to learn and work with the new method, so the change model could be characterized as a learning curve model. These choices were based more on personal experiences with past diffusion and adoption efforts than on a conscious choice of change model. Conflicting interests crippled the implementation somewhat because some powerful customers refused the use of the model. 


\subsubsection{Project 3}

Project 3 had top management support in word but no real support in terms of resources, so skill development suffered from not getting enough time and money. Goals and intentions were directly communicated to target groups, but there was no interaction on how to prioritize. They had made rough plans of how to follow up on the project and perform some kind of monitoring. The project representatives worked together with each target groups in the organization and tailored their individual implementations. This implies the use of a phase introduction strategy combined with a learning curve change model. The new routines were given low priority by affected groups' management, though, as they prioritized their daily operation. Conflicts existed, as the project's steering committee had different (lower) ambitions than the project manager. Additionally, the ISO certifying authority required a different time schedule than did Volvo IT management.

\subsubsection{Project 4}

Project 4's product was never implemented. They had no expressed management support and no goals were communicated or even defined. The product was recommended in company guidelines, but no resources or plan for implementation existed. The product was just expected to diffuse by itself; i.e., the diffusion change model was implicitly used. The product was recommended, but no resources were supplied to support the usage of it. When systems development projects found the product and looked at it, they often considered it too expensive and too complex for most of their needs and chose another unsupported product.

\section{FINDINGS}

The aim of our research was to offer practical advice on how to diagnose diffusion practices within software organizations and to contribute to the understanding of key issues in these practices. First, we discuss our findings regarding key diffusion issues in the diagnosed projects at Volvo IT. Thereafter, we discuss our experiences with the diagnostic techniques used.

In the diagnostic project we identified key diffusion issues at both a general and a project-specific level. The reason for this was to get a nuanced picture of current diffusion practices. 
When investigating the different cases presented above and comparing them with the result from the workshop (figure 2), it is possible to find some common patterns regarding diffusion and adoption.

Management support is important at all involved levels. In the projects studied, management support varied substantially. This of course affected the attention given to the different efforts. However, the major problem related to management support that we found was not lack of support, but lack of clear prioritization between various efforts and conflicting goals between diffusion efforts and operational activities.

None of the projects investigated had tried to identify stakeholders or possible conflicting interests between stakeholders. Thus, there were no preparations for handling conflicts, and some conflicts were not even discovered.

There is a need to improve communication with all actors involved in and affected by a diffusion effort. The level of communication also varies between the cases, but there are examples of almost no communication and of communication through a third party. None of these communication approaches were perceived as successful. In order to control the content and direction of the communication, it is important to have direct interaction with involved actors and stakeholders. The lack of proper stakeholder analyses made it difficult to reach all involved actors.

The level of planning involved in each diffusion effort also varied. There are examples of quite sophisticated implementation planning, but there are also examples of the opposite. Personal experiences with past diffusion efforts seems to be of decisive importance for the level of planning. Thus, the choice of implementation strategy is seldom based on a conscious selection of the most suitable implementation approach in a given situation. We also found that lack of proper planning greatly affected the quality of any estimations regarding time and cost.

We can conclude that diffusion is not recognized as a practice of it's own within department CSM. Consequently, there are no efforts to monitor or evaluate current diffusion efforts. Unless consistent evaluations are undertaken, it will be difficult to structure experiences and extract useful guidelines for future efforts.

In the diagnostic project we used a number of diagnostic techniques. Our experiences with these techniques are summarized on three levels: using the techniques; creating understanding; changing attitudes.

When diagnosing the different diffusion projects, we needed a means to quickly identify problems related to diffusion in department CSM. Diagnostic maps helped us structure the interviews and findings. They also made it easy to focus the interviews on diffusion problems. We did not find the ecological maps as useful as the diagnostic. One reason for this might be 
that ecological maps are aimed at finding solutions to problems and our focus was to identify problems.

Conflicts played a central role in several of the diagnosed projects. Rich pictures provided us with a simple but powerful ability to identify involved actors and relations between them. The interviewees found rich pictures helpful in understanding the situation at hand.

We discovered that a workshop requires a lot of planned facilitation to be successful. Our workshop was organized as a structured brainstorm, and the discussion easily diverged. We as workshop facilitators should have been more active in keeping the discussion on track. Important preparations for a workshop such as ours involve: definition of the question(s) to discuss, a clear definition of the subject, an understanding of the expected results, and knowledge of how to structure these results.

Factor, process, and political research areas provided the theoretical framework needed to prepare the diagnosis, digest the material, and finally, present our findings. It was important to use language and measures that quickly created an understanding for the elements we wanted to emphasize. The theories also gave us knowledge of the huge complexity of diffusion and adoption and the importance of planning an implementation.

Our diagnosis was focused on problems experienced during diffusion efforts. This was a conscious choice partly based on the limited time available and partly on our aim to find out which areas of the current diffusion practice could be improved.

The interviewees and the workshop participants all had a positive attitude toward the focus on diagnosing diffusion and adoption. Among the persons that participated in the diagnoses, there was a common feeling that diffusion and adoption was neglected in CSM's projects. Our effort to diagnose diffusion efforts within CSM has brought up the issue of implementation as an important challenge. As a result, a new project will start in the autumn of 2000, with the intention to improve diffusion practices within CSM. Furthermore, it has been recognized that diffusion and adoption is a very neglected part of the system development process. This will also be addressed in the new project.

Returning to the theory of diffusion and adoption, our study has confirmed previous findings regarding key diffusion and adoption issues. To improve the theoretical framework, we might broaden our studies with knowledge management and organizational learning. 


\section{CONCLUSION}

The diagnosis described in this paper covers three major areas of diffusion issues: factors, processes, and politics. Although all diffusion problems might not be revealed, our research shows that the diagnosis provides insight into important problems with current diffusion practices. Apart from this, the diagnosis also creates an awareness of diffusion issues within the diagnosed organization and provides a baseline for improvement efforts.

The major diffusion and adoption issues that we discovered during our diagnosis of Volvo IT are related to management support, lack of stakeholder analysis, and lack of knowledge about implementation and change strategies. All of these issues can be addressed by improving knowledge about diffusion and adoption and by adding diffusion and adoption as an important issue on the project agenda.

\section{ACKNOWLEDGMENTS}

We thank Susanne Tryde, Ann-Dorte Fladkjaer Nielsen, and Jan PriesHeje for sharing their experiences from Dansk Data. Also, thanks to Kerstin Forsberg, Lars Mathiassen, and Dick Stenmark for constructive comments on this paper.

\section{REFERENCES}

Checkland, P., \& Scholes, J. (1990). Soft Systems Methodology in Action. Chichester: John Wiley \& Sons Ltd.

Cooper, R. B., \& Zmud, R. W. (1990). Information technology implementation research: A technical diffusion approach.

Eason, K. (1988). Chapter 9, Implementation and Support, Information Technology and Organizational Change, Taylor \& Francis.

Fredriksen, J., Honore, P., Krath, F., Krukow, L., \& Fladklaer Nilsen, A. D. (1998). Danske erfaringer med forbedring af softwareprocessen ( $p$. Chapter 5): Center for softwareprocesfobedring, Delta Dansk Elekronik, Lys \& Akustik.

Huff, C. C. (1992). "Elements of a realistic CASE tool adoption budget." Communications of the $A C M, 35,45-54$.

Humphrey, W. (1990). Managing the Software Process: Addison-Wesley Publishing Company, Inc.

Kautz, K. (1995). Information technology transfer and implementation: The introduction of an electronic mail system in a public service organization. In K. Kautz \& J. Preis-Heje (eds.), 
IFIP WG 8.6, working conference on the diffusion and adoption of information technology. Oslo, Norway: Chapman \& Hall.

Lanzara, G. F., \& Mathiassen, L. (1985). "Mapping Situations Within a Systems Development Project." Information and Management, 8.

León, G. (1995). On the diffusion of software technologies: technological frameworks and adoption profiles. In K. Kautz \& J. Preis-Heje (eds.), IFIP WG 8.6, working conference on the diffusion and adoption of information technology (pp. 96-116). Oslo, Norway: Chapman \& Hall.

Lyytinen, K., \& Hirschheim, R. (1987). Information Systems Failures: A Survey and Classification of the Empirical Literature, Oxford Surveys in Information Technology (pp. 257-309): Oxford University Press.

Markus, L. M. (1983). "Power, Politics, and MIS Implementation." Communications of the $A C M, 26,430-444$.

Mathiassen, L., \& Sørensen, C. (1997). A Guide to Manage Software Engineering Technologies. In T. McMaster \& D. Wastell (eds.), Diffusion, Transfer, and Implementation of Information Technology. London: Chapman \& Hall.

McMaster, T., \& Vidgen, R. T. (1995). Implemetation planning for information systems: promoting the transition with a communication strategy. In K. Kautz \& J. Preis-Heje (eds.), IFIP WG 8.6 working conference on the diffusion and adoption of information technology. Oslo, Norway: Chapman \& Hall.

Mitroff, I., \& Linstone, H. A. (1993). The Unbounded Mind: Breaking the Chains of Traditional Business Thinking: Oxford University Press.

Patton, M. Q. (1990). Evaluation and Research Methods. UK: Sage Publications Ltd.

Pressman, R. S. (1997). Software Engineering: A Practitioner's Approach: McGraw-Hill Companies, Inc.

Strauss, A., \& Corbin, J. (1990). Basics of Qualitative Research-Grounded Theory Procedures and Techniques. Newbury Park Ca: Sage Publications.

The Standish Group (1995). Chaos: The Standish Group International, Inc.

Weinberg, G. M. (1997). Quality Software Management: Volume 4, Anticipating Change. New York: Dorset House Publishing.

Yin, R. K. (1994). Case Study Research: Design and Methods: Sage Publications, Ltd. 


\section{APPENDIX}

Table 2. Diagnostic map

\begin{tabular}{|c|c|c|c|}
\hline Problem? & Why? & Consequence? & What can be done? \\
\hline $\begin{array}{l}\text { The model was not } \\
\text { ready for delivery } \\
\text { when it was } \\
\text { released. The review } \\
\text { process, for } \\
\text { example, was not } \\
\text { clearly specified, and } \\
\text { the various reviews } \\
\text { were not } \\
\text { synchronized. } \\
\text { The information } \\
\text { taught in courses } \\
\text { was obsolete after } \\
\text { one month. }\end{array}$ & $\begin{array}{l}\text { A lot of work had to } \\
\text { be redone in order to } \\
\text { adjust to the new } \\
\text { versions. People had } \\
\text { to be educated twice } \\
\text { because the model } \\
\text { changed so much. }\end{array}$ & $\begin{array}{l}\text { Required a lot of } \\
\text { extra time, which } \\
\text { delayed projects. } \\
\text { The model got a bad } \\
\text { reputation. }\end{array}$ & $\begin{array}{l}\text { Pilots should be used } \\
\text { to verify a model } \\
\text { before it is released. } \\
\text { A model should not } \\
\text { be released before it } \\
\text { is completed and } \\
\text { everything is in } \\
\text { place. }\end{array}$ \\
\hline $\begin{array}{l}\text { Not enough } \\
\text { marketing of model } \\
\text { mentors. }\end{array}$ & $\begin{array}{l}\text { With the help of } \\
\text { model mentors, the } \\
\text { projects would have } \\
\text { reduced the time and } \\
\text { effort required. }\end{array}$ & $\begin{array}{l}\text { Increased the time } \\
\text { required to learn and } \\
\text { use the model. } \\
\text { Some projects didn't } \\
\text { find it worth the } \\
\text { effort to use the } \\
\text { model. }\end{array}$ & $\begin{array}{l}\text { If there is limited } \\
\text { support available, it } \\
\text { is a bad idea to make } \\
\text { a model mandatory } \\
\text { for all projects. An } \\
\text { iterative } \\
\text { implementation with } \\
\text { a lot of support is } \\
\text { much better. }\end{array}$ \\
\hline $\begin{array}{l}\text { Unclear, sometimes } \\
\text { conflicting, } \\
\text { messages. }\end{array}$ & $\begin{array}{l}\text { People were } \\
\text { uncertain about what } \\
\text { was true and what } \\
\text { was not. }\end{array}$ & $\begin{array}{l}\text { Required a lot of } \\
\text { extra time. } \\
\text { The model got a bad } \\
\text { reputation. }\end{array}$ & See above. \\
\hline $\begin{array}{l}\text { Learning the model } \\
\text { required a lot of } \\
\text { initial effort because } \\
\text { it was complicated. } \\
\text { There was no } \\
\text { overview of the } \\
\text { model. }\end{array}$ & $\begin{array}{l}\text { Time is money and } \\
\text { projects have a } \\
\text { limited budget. }\end{array}$ & $\begin{array}{l}\text { The model was not } \\
\text { used. }\end{array}$ & $\begin{array}{l}\text { There should be } \\
\text { some form of } \\
\text { introduction and } \\
\text { readers digest that } \\
\text { gives a good } \\
\text { overview of the } \\
\text { model. }\end{array}$ \\
\hline $\begin{array}{l}\text { The model is } \\
\text { designed to handle } \\
\text { the most complex } \\
\text { projects, and there is } \\
\text { no light version } \\
\text { available for small } \\
\text { and simple projects. }\end{array}$ & $\begin{array}{l}\text { It is impossible for } \\
\text { one model to } \\
\text { efficiently control } \\
\text { both large, complex } \\
\text { projects and small, } \\
\text { simple ones. }\end{array}$ & $\begin{array}{l}\text { The model is not } \\
\text { suitable for small } \\
\text { projects and thus is } \\
\text { not used for these. }\end{array}$ & See above. \\
\hline
\end{tabular}


Special requirement: Delivery date was predetermined by management Big Bang introduction was also predetermined.

Management: $\quad$ Not enough support from middle management. Descriptions of consequences were not communicated through the organization. Messages were filtered.

Not enough resources were in place to support Big Bang.

Project control: Projects using the model had not calculated with the extra cost that comes with using a new model.

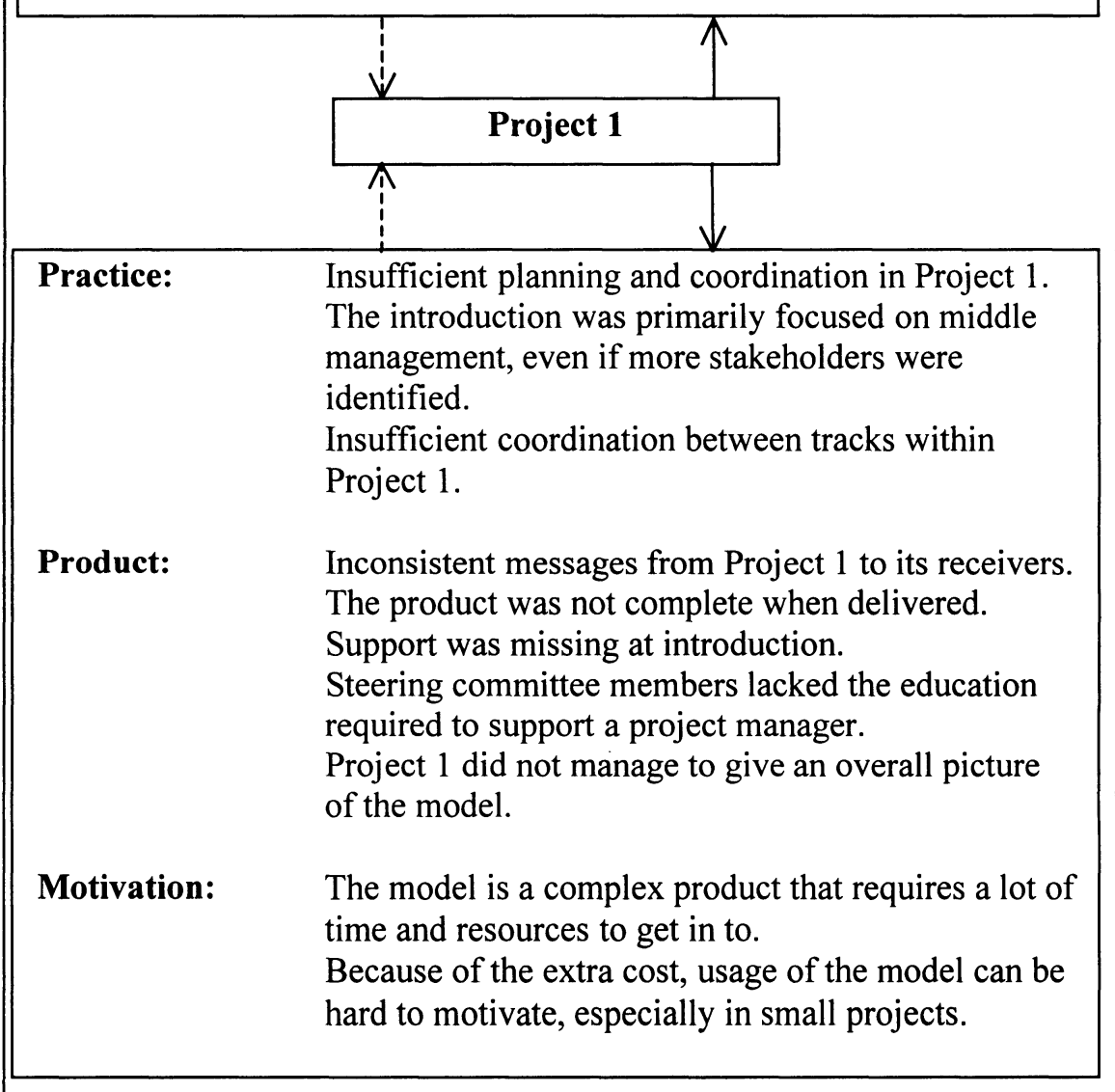

